\title{
Insight from Simulations of Single-Well Injection- Withdrawal Tracer Tests on Simple and Complex Fractures
}

Chin-Fu Tsang ${ }^{1,2}$ and Christine Doughty ${ }^{1}$

\author{
${ }^{1}$ Earth Sciences Division \\ Lawrence Berkeley National Laboratory \\ Berkeley, California 94720, USA \\ ${ }^{2}$ Department of Earth Science and Engineering \\ Imperial College London SW7 2AZ, UK
}

June 2009 


\section{Abstract}

The single-well injection withdrawal (SWIW) test, a tracer test utilizing only one well, is proposed as a useful contribution to site characterization of fractured rock, as well as providing parameters relevant to tracer diffusion and sorption. The usual conceptual model of flow and solute transport through fractured rock with low matrix permeability involves solute advection and dispersion through a fracture network coupled with diffusion and sorption into the surrounding rock matrix. Unlike two-well tracer tests, results of SWIW tests are ideally independent of advective heterogeneity, channeling and flow dimension, and, instead, focus on diffusive and sorptive characteristics of tracer (solute) transport. Thus, they can be used specifically to study such characteristics and evaluate the diffusive parameters associated with tracer transport through fractured media. We conduct simulations of SWIW tests on simple and complex fracture models, the latter being defined as having two subfractures with altered rock blocks in between and gouge material in their apertures. Using parameters from the Äspö site in Sweden, we calculate and study SWIW tracer breakthrough curves (BTCs) from a test involving four days of injection and then withdrawal. By examining the peak concentration $C_{p k}$ of the SWIW BTCs for a variety of parameters, we confirm that $C_{p k}$ is largely insensitive to the fracture advective flow properties, in particular to permeability heterogeneity over the fracture plane or to subdividing the flow into two subfractures in the third dimension orthogonal to the fracture plane. The peak arrival time $t_{p k}$ is not a function of fracture or rock properties, but is controlled by the time schedule of the SWIW test. The study shows that the SWIW test is useful for the study of tracer diffusion-sorption processes, including the effect of the so-called flow-wetted surface (FWS) of the fracture. Calculations with schematic models with different FWS values are conducted and the possibility of direct in situ measurement of FWS with SWIW tests is demonstrated. 


\section{Introduction}

A variety of techniques are available for characterization of the hydrogeology of fractured crystalline rock with low matrix permeability, such as surface surveys, well logging, hydrologic tests, and tracer tests. Hydrologic tests can involve one or multiple wells and tracer tests typically involve two or more wells. In this paper, the single-well injection withdrawal (SWIW) test, a tracer tests utilizing only one well (Schroth et al., 2001; Nordqvist and Gustafsson, 2002; 2004, Gouze et al., 2008), is suggested as a useful means of confirming and adding confidence to site characterization of fractured rock as well as providing information on tracer transport diffusive properties. Similar to many other methods, this method is not intended as a stand-alone way to determine parameters, but may be used in conjunction with other methods to estimate in situ flow and transport parameters at the scale of 1 to $50 \mathrm{~m}$ (or more).

The usual conceptual model of flow and transport through fractured rock involves advection and dispersion through the fracture network coupled with diffusion and sorption into the surrounding rock matrix. Unlike typical two-well tracer tests, SWIW tests, involving reversing flow fields by injection and then withdrawal at the same flow rate, focus on diffusive effects, and their results are ideally independent of advective heterogeneity, flow channeling, and flow dimension. Thus, the breakthrough curve (BTC) is not sensitive to "advective dispersivity" but is dominated by the presence of diffusion. Hence the BTC cannot be fitted well with the usual advection-dispersion equation that does not include a matrix diffusion term. One may note here that Taylor dispersion with molecular diffusion within the pore space, or fracture aperture, is a 
diffusive process, but its effect on fracture flow and transport is small compared with diffusive effects at fracture intersections and fracture-matrix interfaces.

A typical two-well (TW) tracer test known as a convergent radial test involves injection of a pulse of tracer at a small flow rate into one well, while a nearby well is pumped at a much larger rate, producing a nearly radial flow field. In contrast, in a SWIW test one well is used to inject fluid and tracer at a constant rate for a specified period of time, then the same well is used to inject fluid (chase fluid) without tracer for an additional time period. After this, the pump is reversed and the well is used to withdraw fluid at the same rate until most or all of the tracer is recovered. Table 1 summarizes some key features that may be of significance in the analysis of SWIW and TW tracer tests respectively. Compared to a typical two-well tracer test, an SWIW test is expected to produce a higher tracer recovery, be more feasible to conduct in the field, and possibly provide information on the flow wetted surface (FWS) of a fracture network (see below).

The present paper aims at obtaining insight into the SWIW tracer testing by conducting a sensitivity study of SWIW BTCs based on a simple and a complex fracture model. The study focuses on the effects of various parameters on the BTC peak concentration, rather than on the late-time tail. The latter has been the subject of a number of papers (e.g., Haggerty et al., 2001). Effects discussed in those papers generally do not significantly affect BTC peak heights. The next section, Section 2, presents the simple and complex fracture models, following which sensitivity studies of model parameters on SWIW tests are presented in Sections 3 and 4. Section 5 discusses and demonstrates the potential of 
using SWIW data for a direct determination of the so-called Flow-Wetted Surface (FWS), which is an important transport property controlling tracer transport in fractured rocks.

\section{Complex and Simple Fracture Models}

We shall briefly describe the complex fracture model (Tsang and Doughty, 2003) in this section, before presenting in the following two sections the results of simulations of SWIW tracer tests as a function of model parameters. The complex-fracture model for fluid flow and tracer transport incorporates the important physical effects of a realistic fracture, including advection through a heterogeneous fracture plane, partitioning of flow into multiple sub-fractures in the third dimension (i.e., orthogonal to the fracture plane), and diffusion and sorption into fracture-filling gouge, small altered rock matrix blocks within the fracture zone, and the unaltered semi-infinite rock matrix on both sides of the fracture zone (Tsang and Doughty, 2003). It is common, however, to represent the complex fracture by much simpler models consisting of a simple two-dimensional fracture, without sub-fractures in the third dimension and with only the unaltered semiinfinite rock matrix for diffusion and sorption. The simple fracture may have a uniform or heterogeneous transmissivity distribution in its plane, and is bounded on both sides by a homogeneous semi-infinite matrix. Figures 1 and 2 illustrate the complex fracture model

and simple fracture models, respectively. The latter may be considered as special cases of the complex model with appropriate choices of complex model parameters.

A complex fracture model is composed of two sub-fractures, with the flow through the fracture $\mathrm{q}$ being the sum of the flows through the two sub-fractures, $q_{1}$ and $q_{2}$. 
$q=q_{1}+q_{2}$

Let us relate the flows $q_{1}$ and $q_{2}$ by

$q_{2}=\alpha q_{1}$

where $\alpha$ can range from 0 (only a single sub-fracture) to 1 (two identical sub-fractures). The transmissivity over the fracture plane is assumed to be heterogeneous: $T(x, y)$. The fracture aperture distribution is also heterogeneous, with aperture $b(x, y)$ related to $T(x, y)$ through the cubic law.

The complex fracture model assumes possible diffusion and sorption into three populations: fracture-filling gouge, small altered rock matrix blocks within the fracture zone, and unaltered semi-infinite rock matrix on both sides of the fracture. The parameters characterizing the transport are fracture aperture $b$, matrix porosity $\phi_{\mathrm{m}}$, and effective matrix diffusivity $D_{e}$, which is defined as the product of free-water diffusivity $D_{f w}$, matrix tortuosity $\tau$, and $\phi_{\mathrm{m}}$. For a sorbing tracer, the product of rock density $\rho_{\mathrm{p}}$ and sorption coefficient $K_{d}$ replaces $\phi_{\mathrm{m}}$ where it appears as an independent parameter, but not within $D_{e}$. Each of the three populations has its own values of $\phi_{\mathrm{m}}, \tau$, and $\rho_{\mathrm{p}} K_{d}$, with the two finite-size populations having each its own characteristic length scale denoted $2 r_{m}$. Two alternatives are considered for the simple fracture model: the first is a single fracture with a uniform transmissivity whereas the second is a single fracture with a 
heterogeneous transmissivity distribution $T(x, y)$. Each simple model includes advection through a planar fracture and diffusion and sorption into a homogeneous semi-infinite rock matrix. No gouge or small altered blocks are considered. The simple fracture models are special cases of the complex model obtained by setting $\alpha=0$ and the populations of gouge and small altered block equal to zero.

A numerical model is used to simulate the fluid flow field through the simple or complex fracture, which may have a spatially heterogeneous transmissivity distribution, based on a rectangular finite difference grid. The central portion of the model, where the wells are located and where the tracer is expected to remain, has high spatial resolution. Beyond this region, the model becomes coarser, and extends a great distance to constant-pressure boundaries. Then a particle-tracking algorithm is used to calculate tracer advection through the fracture, including the distribution of particles among sub-fractures. In order to minimize numerical dispersion that occurs while calculating reversible advective transport in the fracture plane, we employ a special procedure for modeling the flow reversal that happens during a SWIW test. During the injection period the advection calculation is normal — particle advection from one cell to its neighboring cells occurs based on the finite-difference calculation of the flow velocities between these cells. If the flow direction is not parallel to the grid orientation, the destination cell is chosen probabilistically from among all the downstream neighboring cells, with probability proportional to the flow rate into each cell. For each particle, the sequence of cells traversed is recorded. Then, for advection during the withdrawal period, the sequence of cells traversed by the particle during injection is reversed. Thus, the advective part of 
transport during the injection period is exactly reversed for the withdrawal period, properly simulating the physical situation.

Diffusion and sorption into the different populations making up the surrounding rock matrix are calculated probabilistically by inverting semi-analytical solutions (Tsang and Tsang, 2001; Tsang and Doughty, 2003) to determine delay times that represent diffusion and sorption. Over the course of the development of the complex fracture model, three different conceptual models, $\mathrm{C} 1, \mathrm{C} 2$ and $\mathrm{C} 3$, have been considered to describe how the different populations operate relative to each other (Figure 3). In conceptual model C1 (Tsang and Doughty, 2003; Doughty and Uchida, 2005), for each particle at any given time step, diffusion and sorption occur for only one of the three populations, chosen probabilistically (sum total of probability being unity) based on given proportions of each population. This conceptualization implies that all populations block each other. Thus, when finite populations (gouge and small altered blocks) are saturated with tracer and cannot receive any more tracer, the particle does not have an opportunity to diffuse into the semi-infinite rock matrix instead. Conceptual model C2 (Tsang and Doughty, 2007; Tsang et al., 2008) considers two-level diffusion. At the first level, each particle chooses one of the two finite populations probabilistically $(\Sigma \mathrm{P} \leq 1)$ and a tentative delay time $t_{1}$ is calculated. At the second level, diffusion into the semi-infinite matrix is calculated and a second tentative delay time $t_{2}$ is obtained. We then take the maximum of $t_{1}$ and $t_{2}$. This conceptualization implies that only the two finite populations block each other. When the finite populations become saturated with tracer, the particle does have an opportunity to diffuse into the semi-infinite matrix instead. The conceptual model $\mathrm{C} 2$ has the advantage 
over $\mathrm{C} 1$ in that the tracer BTCs tend to the semi-infinite case for large times, when the finite populations are saturated.

In this paper, we propose the conceptual model C3, in which each particle sees all three populations at each time step weighted by its own effective contact area. Taking the effective contact area with the semi-infinite matrix to be unity, the effective contact areas for the finite populations are each less than one. Delay times for each population are then summed. This conceptualization implies that none of the populations block each other. Each particle always has the opportunity to diffuse into all populations. This approach not only yields the semi-infinite results at large times after the saturation of the finite populations, but also provides the possibility of representing, at least approximately, the multi-layer effect of tracer migration into the semi-infinite matrix after passing through a rock layer or "fracture skin" of a finite thickness.

Table 2 and Table 3 summarize the parameters of the simple and complex fracture models. They are extracted from an analysis of a tracer test in granitic rock at Äspö, Sweden (Doughty and Uchida, 2005) and thus correspond to realistic field properties. Values for two tracers are shown, non-sorbing tritiated water HTO and slightly sorbing strontium Sr, although for the present study, only HTO is considered. 


\section{Design of Sensitivity Studies to Examine Dependence of SWIW BTCs on Fracture Parameters}

For two-well tracer tests, key features of the BTCs arising from the transport processes are the peak height $C_{p k}$, the peak arrival time $t_{p k}$, slope of the late-time tail, the tracer recovery factor, and perhaps also the tracer "first" arrival time $t_{0}$, defined, for instance, as

the time for which $C \approx 10^{-3} C_{p k}$. For the SWIW tests, the key features are peak height $C_{p k}$, slope of the late-time tail, and the recovery factor. The timing of the peak arrival is primarily set by the time schedule of the SWIW test. In the present SWIW sensitivity studies, we focus on the BTC peak height or peak concentration.

Our basic calculations involve a $15 \mathrm{~m}$ x $15 \mathrm{~m}$ fracture plane discretized into regular square grid blocks with $0.1 \mathrm{~m}$ grid spacing, and a non-sorbing tracer (HTO). For particle tracking, 200,000 particles are used in all cases.

The majority of the results shown are for the simple heterogeneous model (no subfractures, gouge, or small altered blocks), assuming a range of values for $D_{e}$ and several different fracture heterogeneities. The range of $D_{e}$ values will be called apparent diffusivity $D_{A}$ to distinguish them from the $D_{e}$ value obtained from laboratory measurements on rock cores, which is denoted $D_{e(L a b)}$. Fracture heterogeneity, represented by transmissivity distribution $T(x, y)$, is characterized by its geometric mean $<T>$, the standard deviation $\sigma$ of $\log _{10} T$, and, spatial correlation length $\lambda$. A uniform medium $(\sigma=0)$, and several heterogeneous cases $(\sigma \neq 0)$ were simulated. Three shortcorrelation length cases were considered, each with $\lambda=0.3 \mathrm{~m}$ for grid cells of low 
permeabilities and $\lambda=1 \mathrm{~m}$ for those with high permeabilities, and with $\sigma$ ranging from 0.57 to 1.77 . Additionally, five long-correlation length cases were considered, with $\lambda=2$ $\mathrm{m}$ for low permeabilities and $\lambda=6 \mathrm{~m}$ for high permeabilities, and with $\sigma$ ranging from 0.99 to 1.36 .

A series of calculations using the complex fracture model were also performed, in which the rock matrix surrounding the fracture is assumed to consist of 25\% gouge and $25 \%$ small blocks of altered matrix material. The gouge and small blocks do not shield the semi-infinite matrix and so particles have a chance to diffuse into the semi-infinite matrix at every time step. Sensitivity calculations using the complex model assume different values for the fracture structure parameter $\alpha$ and different $\sigma$ values for short-correlation length fracture heterogeneity.

The basic SWIW procedure assumed in this paper is to inject for four days into one cell in the center of the model domain, during which tracer is injected for the first day, followed by three days of untraced water (called chase fluid) at the same rate. The grid design and injection rate are chosen so the tracer plume remains in the high-resolution central portion of the model domain. Following four days of injection, fluid is produced from the same cell and at the same rate for 12 or more days.

To compare the trends of results from SWIW and from TW tests, a simple TW tracer convergent test is also simulated in which the injection and withdrawal points are $10 \mathrm{~m}$ apart. Injection occurs for one day at a small rate, and the other well is continuously 
pumped with a withdrawal rate chosen to give a similar flow path length through the fracture and a similar peak arrival time as those of the SWIW test. The TW calculations are performed only to show trends of results, against which insight into SWIW BTC results may be gained.

One important point concerning the difference between the SWIW and TW tests is illustrated in Figure 4. In the TW tests, as tracer flows from one well to the other, it is continually exposed to new gouge and small altered blocks, which continue to provide opportunity for diffusion and sorption (Figure 3). In contrast, in the SWIW test, only half as much gouge and small altered blocks are encountered by the particles, and they are encountered twice, during both the out and back parts of the flow. Thus they are more likely to become saturated and unable to provide further diffusion and sorption capacity. From Neretnieks (2007, Equation 5 and Figure 5) it can be shown that gouge and small altered blocks with sizes given in Table 3 can be saturated in the order of one day or so. Therefore, the gouge and small altered blocks become saturated in the SWIW test and they are much less likely to veil the effects of diffusion into the semi-infinite rock matrix on BTCs than in the TW test case. This points to the interesting and important possibility of using SWIW tests to determine the diffusion parameters of interest, for long-term predictions, i.e., those of the semi-infinite matrix. 


\section{Results of Sensitivity Studies}

\subsection{Simple Fracture with Small Correlation Range Cases}

Figure 5 shows snapshots of the tracer distribution in the fracture plane for a simple model with semi-infinite matrix diffusion, for four values of $\sigma$ and the case of short correlation length. Particle density at every point is shown, which includes both the particles in the fracture and those already diffused into the matrix. As $\sigma$ increases, indicating that the transmissivity distribution is becoming increasingly heterogeneous, the tracer distribution becomes increasingly heterogeneous as well.

Figure 6 shows the corresponding breakthrough curves (BTCs). Peak height $C_{p k}$ is not very sensitive to $\sigma$ for $\log _{10} T$ values ranging from 0 to 1.77 , which is quite a wide range. The BTC tail shows the $-3 / 2 \log$ slope, characteristic of tracer slowly being recovered by diffusion from the semi-infinite rock matrix on either side of the fracture (Tsang, 1995).

\subsection{Simple Fracture with Long Correlation Range Cases}

Figure 7 shows snapshots of tracer distribution for three long-correlation cases for $\sigma \sim$ 1.35 (recall $\sigma$ is standard deviation of $\log _{10} T$ ). Two of the cases have an isotropic correlation length and the third has an anisotropic correlation length, resulting in an anisotropic transmissivity distribution. Similar to the short-correlation results, the peak height is not very sensitive to $\sigma$ value. This is shown in Figure 8, where the peak concentration is plotted as a function of $\sigma$, together with results of the short correlation range cases from Figure 6. On the right-hand side of Figure 8 is shown for comparison 
the corresponding results from simulation of a two-well tracer test, which display not only a strong dependence of the peak concentration as a function of $\sigma$, but also variations due to different realizations of the flow field. The figure also shows the complex fracture results, which will be discussed in the next subsection.

\subsection{Complex Fracture Cases}

A complex fracture differs from the simple fracture in two aspects: firstly, the existence of gouge and small altered blocks which provide additional diffusion and sorption capacity, and secondly, the possibility of two subfractures whose flows are related to each other through the parameter $\alpha$.

The gouge and small altered blocks provide extra diffusion and sorption capacity beyond that of the semi-infinite matrix. However, as remarked above in reference to Figure 4, these materials are likely to be saturated with tracer during the four-day SWIW tracer experiments. Then their main role will be mainly to slow down the tracer front movement and, since the SWIW test time schedule is fixed, the radial distance of the tracer front will be reduced. Then, with the smaller tracer plume radius, the area (analogous to the "flowwetted surface") over which diffusion into the semi-infinite matrix occurs will be decreased, with the result of higher peak concentration than for the simple fracture case. The results are shown in Figure 8, which shows that the peak concentration in the complex fracture case is still not very sensitive to $\sigma$.

Figure 9 illustrates the effect of fracture structure parameter $\alpha$ on the tracer BTC peak height for the case of two subfractures with or without gouge and small altered blocks. 
The subfractures can be uniform or heterogeneous in transmissivity over their planes. The results indicate that $\alpha$ has a very minor effect on peak height. For comparison, a corresponding case for a TW test is shown on the right-hand side of Figure 9, showing a strong dependence on $\alpha$ that is symmetrical around $\alpha=0.5$, as one would expect.

Figure 10 shows the BTCs for a simple and a complex fracture model. Both display a logarithmic slope of $-3 / 2$ for the late-time tail. However, for the complex fracture, the first part of the slope beyond the peak is much steeper. This is due to the interplay between the diffusion into the finite rock blocks that become saturated with tracer during the experiment and the diffusion into the semi-infinite rock matrix. The BTC as shown can thus be used to distinguish between the two processes, allowing the possibility of determining the diffusion parameters of the semi-infinite matrix, which plays the main role for long term retardation of tracer migration. This is in contrast to two well tests, where the presence of advective dispersion processes makes this much more difficult (Tsang et al., 2008).

Also, since the $-3 / 2$ slope is not seen until some time after the BTC peak, it means that, if monitoring is not continued long enough, an erroneous slope might be extrapolated, as shown by the black lines in Figure 10. Further, if such a line is used to estimate tracer recovery factor, then the tracer represented by the shaded portion of Figure 10 will not be accounted for.

Figure 11 summarizes the effects of various parameters on peak height for models with no gouge or altered rock blocks. Here they are shown as a function of $D_{A}$, the apparent 
diffusivity value, which in an ideal case should be equal to $D_{e(L a b)}$. The general conclusion is that the dependence of BTC peak concentration on fracture heterogeneity and $\alpha$ is small, whereas the dependence on $D_{A}$ is larger.

\section{Potential Method to Determine FWS Using SWIW}

\section{Tests}

As demonstrated in the sensitivity studies presented in Section 4, channeling, heterogeneity, and flow dimension create highly variable spatial tracer distributions, but do not strongly impact SWIW BTCs, which are mainly controlled by matrix diffusion and sorption. An important parameter is the "flow wetted surface," (FWS), the area of rock matrix contacted by the flowing tracer, through which diffusion and sorption may occur. For the simple fracture model it is well known (see, e.g., Tsang and Tsang, 2001) that matrix diffusion depends on the product FWS $\mathrm{x}\left(D_{e(L a b)}\right)^{1 / 2}$, where $D_{e(L a b)}$ is the effective diffusivity value obtained from laboratory analysis of core-scale samples of the unaltered semi-infinite rock matrix. This simple dependence may provide a way to directly estimate FWS using SWIW tests, since SWIW BTCs are not "confused" with advective dispersion as is the case with two-well tracer tests.

Let us define an apparent diffusivity $D_{A}$ as

$D_{A}^{1 / 2}=\operatorname{FWS}\left(D_{e(L a b)}\right)^{1 / 2}$,

so that 
$\mathrm{FWS}=\left(D_{A} / D_{e(L a b)}\right)^{1 / 2}$.

The value of $D_{A}$ can be estimated by parameter fitting to an experimental SWIW BTC. One way is to take the SWIW peak concentration value and use Figure 11 to infer the value for $\left(D_{A} / D_{e(L a b)}\right)$, see the horizontal and vertical arrowed lines in the figure. Then, with a laboratory-measured value of $D_{e(L a b)}$, a value for FWS can be obtained by the above equation.

To test this approach, we consider SWIW tests conducted in models with different flow geometries, as shown in Figure 12. In each case, parameters are chosen so that for the same pressure change $\Delta P$, the same flow rate $Q$ is obtained, which implies, from the cubic law for fracture flow, that

$w_{1} b_{1}{ }^{3}=w_{2} b_{2}{ }^{3}$.

Thus, specifying the values of widths $w_{1}$ and $w_{2}$ prescribes the ratio of apertures $b_{1}$ and $b_{2}:$

$b_{1} / b_{2}=\left(w_{2} / w_{1}\right)^{1 / 3}$.

Now, if we assume these two cases of flow geometries are used for SWIW tests employing identical values of $Q \Delta t_{i n j}$, then 
$Q \Delta t_{i n j}=w_{1} b_{1} L_{1}=w_{2} b_{2} L_{2}$

Since FWS $=w L$,

$$
\frac{\mathrm{FWS}_{1}}{\mathrm{FWS}_{2}}=\frac{w_{1} L_{1}}{w_{2} L_{2}}=\frac{b_{2}}{b_{1}}
$$

Then, we have

$$
\sqrt{\frac{D_{A 1}}{D_{A 2}}}=\frac{\mathrm{FWS}_{1}}{\mathrm{FWS}_{2}}=\left(\frac{L_{1} w_{1}}{L_{2} w_{2}}\right)=\frac{b_{2}}{b_{1}},
$$

for the same value of $D_{e}(L a b)$.

To construct multiple schematic models with different flow geometries, and hence different values of FWS, we proceed as follows. We keep the same SWIW schedule for all cases: inject for 1 day at $Q=10^{-7} \mathrm{~m}^{3} / \mathrm{s}$, chase for 3 days using the same $Q$, then withdraw at the same $Q$ until all tracer is withdrawn. We consider various flow geometries (Figure 12) with a single value of $D_{A}=D_{e(L a b)}$. The model has closed sides and a constant pressure at the two end boundaries. A single injection/withdrawal point is located in the middle. The model uses a uniform $\mathrm{T}$ field with small numerical dispersion. The width $w$ varies $(15,10,15,20,40 \mathrm{~m})$. The aperture $b$ is then calculated by keeping 
$w b^{3}$ constant. Hence FWS varies among the models. Table 4 summarizes the cases considered, showing that FWS (or $b$ ) varies by a factor of two among the cases.

Figure 13 shows the BTCs obtained from the five models. Note that peak arrival times and tail slopes do not vary, while the peak heights do vary. Hence matching $C_{p k}$ would provide a simple way to match BTC. All the models use the same value of $D_{A}$ (here we set $D_{A}=D_{e(L a b))}$.

Next, using the Case 3 flow geometry, a range of $D_{A}$ values are used to simulate SWIW tests, creating BTCs and hence $C_{p k}$ values as a function of $D_{A}$, as shown by the red symbols in Figure 14. The smooth variation of $C_{p k}$ with $D_{A}$ enables a power-law (black curve) to be fit to the $C_{p k}$ values. Then the $C_{p k}$ values obtained for the various flow geometries are plotted (blue lines), and the corresponding $D_{A} / D_{e(L a b)}$ values are read off the plot. Table 5 summarizes the results. The agreement between the square root of $D_{A} / D_{e(L a b)}$ and the input values of $b$ ratio is very good.

The conclusion of this section is that the SWIW tests show a good potential for direct in situ measurements of FWS, a key factor in tracer transport in fractured rocks, on the scale of the SWIW tests, i.e., order of 1-50 m. Practical field conditions are often much more complex involving different types of diffusive processes, but perhaps the FWS thus determined can be considered as an effective value accounting for the integrated effects of various sources of diffusion over this spatial scale. This interpretation is possible because of the characteristic of SWIW test results of not being sensitive to advective 
heterogeneities and flow dimensions, thus providing an opportunity for measurements of effective FWS parameter, to which SWIW results are indeed sensitive to.

\section{Conclusions}

Sensitivity studies of SWIW tests on simple and complex fracture models have been conducted. Results of SWIW peak height $C_{p k}$ for a variety of models confirm that $C_{p k}$ is not very sensitive to fracture advective properties, such as transmissivity heterogeneity. Also, peak arrival time $t_{p k}$ is not very sensitive to fracture or rock properties, but rather is controlled by the schedule of the SWIW test. Tracer recovery factor is generally determined by extrapolating the tracer BTC, assuming a straight line on a log-log plot. However, for the limited time duration of typical tracer tests, the slope of the trailing edge of the peak can be misleading and lead to an underestimate of tracer recovery factor.

For parameters from the Äspö site in Sweden, we find that SWIW BTCs show a distinct $-3 / 2$ slope in log plot in the tail region preceded by a much sharper peak. This shows the interplay between the effects of finite gouge/blocks, and the semi-infinite rock matrix. Thus analysis of SWIW tests has the potential of separating the two sets of parameters and providing parameters appropriate for predictions of long-term tracer transport which is mainly controlled by properties of the semi-infinite matrix on both sides of the fracture.

Studies using schematic simple fracture models with uniform transmissivity fields demonstrate the possibility of direct measurement of FWS from SWIW tests. They point 
to an effective and interesting approach for determination of this important transport property in situ on the scale of SWIW tests.

\section{Acknowledgements}

We thank Andrea Cortis, Joel Geier, Kenzi Karasaki and Yvonne Tsang for their careful review of this paper. The first author is grateful for the many discussions with members of the INSITE Core Group under the auspices of the Swedish Radiation Safety Authority (SSM, previously SKI). This work was jointly supported by SSM and the Japan Atomic Energy Agency (JAEA) under the Binational Research Cooperative Program between JAEA and the U.S. Department of Energy. The work was performed under the auspices of the U.S. Department of Energy through Contract No. DE-AC02-05CH11231.

\section{Bibliography}

Deutsch, C.V. and A.G. Journel, GSLIB: Geostatistical software library and user's guide, $2^{\text {nd }}$ ed., Oxford Univ. Press, New York 1998.

Doughty, C. and M. Uchida, PA calculations for feature A with third-dimension structure based on tracer test calibration, Rep. IPR-04-33, Swedish Nuclear Fuel and Waste Management Co. (SKB), Stockholm, 2005.

Gouze, P., T. Le Borgne, R. Leprovost, G. Lods, T. Poidras, and P. Pezard, Non-Fickian dispersion in porous media: 1 . Multiscale measurements using single-well injection withdrawal tracer tests, Water Resour. Res., 44, W06426, doi:10.1029/2007WR006278, 2008. 
Haggerty, R., S.W. Fleming, L.C. Meigs, S.A. McKenna, Tracer tests in fractured dolomite. 2. Analysis of mass-transfer in single-well injection-withdrawal tests. Water Resources Research 37, no. 5: 1129-1142, 2001.

Mazurek, M., P. Bossart, and J. Hermanson, Classification and characterization of waterconducting features at Aspo, in Proceedings of International Seminar First TRUE Stage Rep. TR-01-24, pp. 203-208, Swedish Nuclear Fuel and Waste Management Co. (SKB), Stockholm, 2001.

Neretnieks, I. Single-well injection-withdrawal tests (SWIW) in fractured rock some aspects on interpretation, SKB Report R-07-54. Swedish Nuclear Fuel and Waste Management Co. (SKB), Stockholm, 2007.

Nordqvist, R., and E.Gustafsson, Single-well injection-withdrawal tests (SWIW). Literature review and scoping calculations for homogeneous crystalline bedrock conditions. SKB R-02-34, Swedish Nuclear Fuel and Waste Management Co. (SKB), Stockholm, Sweden, 2002.

Nordqvist, R. and E.Gustafsson, Single-well injection-withdrawal tests (SWIW). Investigation and evaluation aspects under heterogeneous crystalline bedrock conditions. SKB R-04-57. Swedish Nuclear Fuel and Waste Management Co. (SKB), Stockholm, Sweden, 2004.

Schroth, M.H., J.D. Istok, R. Haggerty, In situ evaluation of solute retardation using single-well push-ull test. Advances in Water Resources 24: 105-117, 2001.

Tsang, Y.W., Study of alternative tracer tests in characterizing transport in fractured rocks. Geophysical Research Letters 22, no. 11: 1421-1424, 1995. 
Tsang, Y.W. and C.F. Tsang, A particle-tracking method for advective transport in fractures with diffusion into finite matrix blocks, Water Resources Research, 37(3), 831-835, 2001.

Tsang, C.-F. and C. Doughty, A particle-tracking approach to simulating transport in a complex fracture, Water Resources Research, 39(7), 1174, doi:10.1029/2002WR001614, 2003.

Tsang, C.-F. and C. Doughty, Some insights from simulations of SWIW tests on a complex fracture, Rep. SKI-INSITE TRD-07-06, SKI, Stockholm, 2007.

Tsang, C.-F., C. Doughty, and M. Uchida, Simple model representations of transport in a complex fracture and their effects on long-term predictions, Water Resources Research, 44, W08445, doi:10.1029/2007WR006632, 2008. 


\section{List of Tables}

Table 1. Key features of significance in TW and SWIW tracer test analysis.

Table 2. Parameters of fracture transmissivity distribution (Doughty and Uchida, 2005).

Table 3. Diffusion parameters of multiple rock populations (Doughty and Uchida, 2005).

Table 4. Schematic model parameters. Case 3 is considered as the base case.

Table 5. Comparison of $D_{A} / D_{e(L a b)}$ values read off Figure 14 with the ratio of $w L$ given in Table 4. 


\section{List of Figures}

Figure 1. Complex fracture model (Tsang and Doughty, 2003; Mazurek et al., 2001).

Figure 2. Schematic view of two versions of simple fracture model.

Figure 3. Three alternative prescriptions $\mathrm{C} 1, \mathrm{C} 2$ and $\mathrm{C} 3$ for calculating diffusion/sorption into the semi-infinite and finite populations. $\mathrm{C} 3$ is used in this paper.

Figure 1. Schematic diagram of particle travel path during a two-well test (a) and a SWIW test (b). Arrows represent advection through the fracture and circles and ovals represent finite populations into which diffusion and sorption may occur. The semiinfinite rock matrix, also present, is not shown in this figure. I and W indicate injection and withdrawal wells respectively.

Figure 5. SWIW tracer distributions over the center part of the flow domain at 1, 4, 8 and 12 days for the simple fracture model employing various $\sigma$ values for short-correlation length heterogeneity.

Figure 6. Tracer BTCs for the simple model with different values of $\sigma$ representing different levels of short-correlation heterogeneity. The dashed line shows a log slope of $-3 / 2$.

Figure 7. SWIW tracer distributions over the center part of the flow domain at 1, 4, 8 and 12 days for the simple fracture model employing various $\sigma$ values for long-correlation length heterogeneity 
Figure 8. Peak concentration from the tracer BTCs for the simple and complex fracture models with short- and long-correlation length heterogeneity for different $\sigma$ values. Left frame: SWIW tests; right frame: two-well (TW) tests.

Figure 9. Peak concentration from the tracer BTCs for various values of $\alpha$, for a uniform and heterogeneous $T$ fields. Left frame: SWIW tests; right frame: two-well (TW) tests

Figure 10. Comparison of tracer BTCs for simple and complex fracture models. If monitoring only continues for 15 days, the true late-time slope will not be observed.

Figure 11. The effect of various parameters on peak concentration as a function of $D_{A}$ value for models with no gouge or small altered blocks. The different symbols represent cases with different values of $\sigma$ and $\alpha$ parameters. For all cases with $D_{A} \neq D_{e(L a b)}, \alpha=0$.

Figure 12. Schematic flow geometries with different values of FWS.

Figure 13. Tracer BTCs for schematic models with different flow geometries.

Figure 14. $C_{p k}$ as a function of $D_{A} / D_{e(L a b)}$ for a single flow geometry (red symbols) and corresponding spline fit (red line) and power-law fit (black line). $C_{p k}$ values obtained using $D_{e(L a b)}$ and different flow geometries are shown as blue lines. The intersection of the blue line and the black curve determines apparent diffusivity $D_{A}$. 
Table 1. Key features of significance in TW and SWIW tracer test analysis.

\begin{tabular}{|c|c|c|}
\hline Features & TW & SWIW \\
\hline Taylor dispersion within fracture aperture & $\begin{array}{l}\text { Relatively small } \\
\text { effect }\end{array}$ & $\begin{array}{l}\text { Relatively small } \\
\text { effect }\end{array}$ \\
\hline \multicolumn{3}{|l|}{ Diffusion in and out of: } \\
\hline Rock gouge in flow paths & Yes & $\begin{array}{l}\text { Yes (less if gouge } \\
\text { becomes saturated } \\
\text { by tracer) }\end{array}$ \\
\hline Coating/alteration/rock matrix & Yes & $\begin{array}{l}\text { Yes (less if material } \\
\text { becomes saturated } \\
\text { by tracer) }\end{array}$ \\
\hline Stagnant water and infill & Yes & $\begin{array}{l}\text { Yes (less if water } \\
\text { becomes saturated } \\
\text { by tracer) }\end{array}$ \\
\hline $\begin{array}{l}\text { Rock matrix on two sides of fracture } \\
\text { directly or via stagnant water }\end{array}$ & Yes & Yes \\
\hline Sorption/Desorption reaction rate & Yes & Yes \\
\hline Regional flow gradient & Yes & Yes, more \\
\hline Lost tracer (impact on Recovery Factor) & Yes & Yes, less \\
\hline Flow variations: channeling etc. & Yes & No \\
\hline Knowledge of region of study & Yes & Less \\
\hline Scale & Defined & Less \\
\hline Diffusion, effective & Yes & Yes, dominant \\
\hline Feasibility for conducting the test & More difficult & Much easier \\
\hline
\end{tabular}


Table 2. Parameters of fracture transmissivity distribution (Doughty and Uchida, 2005).

\begin{tabular}{|l|l|}
\hline Parameter & Value \\
\hline Fracture dimensions (m) & $15,15,0.02$ \\
nx, ny, nz (number of grid blocks in central & $150,150,1$ \\
\hline $\begin{array}{l}\Delta x, \Delta y, \Delta z(\mathrm{~m}) \text { (grid spacing in central portion of } \\
\text { model) }\end{array}$ & $0.10,0.10,0.02$ \\
\hline $\begin{array}{l}\text { Sequential indicator simulation (Deutsch and Journel, 1998) using a } \\
\text { CDF for log } 10 T \text { based on } 15 \text { well-test analyses for } 5 \text { boreholes }\end{array}$ & $-6.5,1.35$ \\
\hline $\begin{array}{l}\text { Mean, standard deviation of log } 10 T\left(T \text { in } \mathrm{m}^{2} / \mathrm{s}\right) \\
\text { Spherical variogram range for lower } 80 \% \text { of } T \\
\text { values (m) }\end{array}$ & 0.3 \\
\hline $\begin{array}{l}\text { Spherical variogram range for higher } 20 \% \text { of } T \\
\text { values (m) }\end{array}$ & 1 \\
\hline $\begin{array}{l}\text { Mean fracture aperture ( } \mu \mathrm{m}) \\
\text { Fracture structure parameter } \alpha\end{array}$ & 77 \\
\hline
\end{tabular}


Table 3. Diffusion parameters of multiple rock populations (Doughty and Uchida, 2005).

\begin{tabular}{|c|c|c|c|}
\hline & Fault gouge & $\begin{array}{l}\text { Small altered blocks } \\
\text { within fracture zone }\end{array}$ & $\begin{array}{l}\text { Semi-infinite matrix } \\
\text { (unaltered rock outside } \\
\text { fracture zone) }\end{array}$ \\
\hline $\begin{array}{l}\text { Effective contact } \\
\text { area }\end{array}$ & 0.25 & 0.25 & 1 \\
\hline Radius $r_{m}(\mathrm{~m})$ & $5 \cdot 10^{-4}$ & 0.005 & $\begin{array}{l}\text { not applicable } \\
\text { (essentially infinite) }\end{array}$ \\
\hline Porosity $\phi_{\mathrm{m}}$ & 0.20 & 0.01 & 0.004 \\
\hline Tortuosity $\tau$ & 0.625 & 0.0625 & 0.05 \\
\hline Density $\rho_{\mathrm{p}}\left(\mathrm{kg} / \mathrm{m}^{3}\right)$ & 2700 & 2700 & 2700 \\
\hline $\begin{array}{l}D_{f w}\left(\mathrm{~m}^{2} / \mathrm{s}\right) \text { for free } \\
\text { water }\end{array}$ & & $\begin{array}{l}\text { HTO: } 2.35 \cdot 10^{-9} \\
\text { Sr: } 7.90 \cdot 10^{-10}\end{array}$ & \\
\hline$D_{e}\left(\mathrm{~m}^{2} / \mathrm{s}\right)$ & $\begin{array}{l}\text { HTO: } 2.9 \cdot 10^{-10} \\
\text { Sr: } 9.9 \cdot 10^{-11}\end{array}$ & $\begin{array}{l}\text { HTO: } 1.5 \cdot 10^{-12} \\
\text { Sr: } 4.9 \cdot 10^{-13}\end{array}$ & $\begin{array}{l}\text { HTO: } 4.7 \cdot 10^{-13} \\
\text { Sr: } 4.0 \cdot 10^{-14}\end{array}$ \\
\hline$K_{d}\left(\mathrm{~m}^{3} / \mathrm{kg}\right)$ & $\begin{array}{l}\text { HTO: } 0 \\
\text { Sr: } 1.5 \cdot 10^{-4}\end{array}$ & $\begin{array}{l}\text { HTO: } 0 \\
\text { Sr: } 4.7 \cdot 10^{-6}\end{array}$ & $\begin{array}{l}\text { HTO: } 0 \\
\text { Sr: } 4.7 \cdot 10^{-6}\end{array}$ \\
\hline
\end{tabular}


Table 4. Schematic model parameters. Case 3 is considered as the base case.

\begin{tabular}{|c|c|c|c|}
\hline Case & $w(\mathrm{~m})$ & $b(\mathrm{~m})$ & $b_{3} / b$ \\
\hline 1 & 5 & $7.535 \mathrm{e}-5$ & 0.69 \\
\hline 2 & 10 & $5.981 \mathrm{e}-5$ & 0.87 \\
\hline 3 & 15 & $5.224 \mathrm{e}-5$ & 1.00 \\
\hline 4 & 20 & $4.747 \mathrm{e}-5$ & 1.10 \\
\hline 5 & 40 & $3.768 \mathrm{e}-5$ & 1.39 \\
\hline
\end{tabular}


Table 5. Comparison of $D_{A} / D_{e(L a b)}$ values read off Figure 14 with the ratio of $w L$ given in Table 4.

\begin{tabular}{|c|c|c|c|c|}
\hline Case & $\begin{array}{c}\text { c } C_{p k} \\
\text { (Figure 14 } \\
\text { blue lines) }\end{array}$ & $\begin{array}{c}D_{A} / D_{e(L a b)} \\
\text { (from Figure 14) }\end{array}$ & $\begin{array}{l}\text { Square root of } \\
\qquad D_{A} / D_{e(L a b)} \\
\text { from Figure } 14\end{array}$ & $\begin{array}{c}\text { Ratio of } w L=b_{3} / b \\
\text { (from Table 4) }\end{array}$ \\
\hline 1 & 0.209 & 0.54 & 0.73 & 0.69 \\
\hline 2 & 0.172 & 0.80 & 0.89 & 0.87 \\
\hline 3 & 0.155 & 1.00 & 1.00 & 1.00 \\
\hline 4 & 0.143 & 1.22 & 1.10 & 1.10 \\
\hline 5 & 0.122 & 1.81 & 1.35 & 1.39 \\
\hline
\end{tabular}




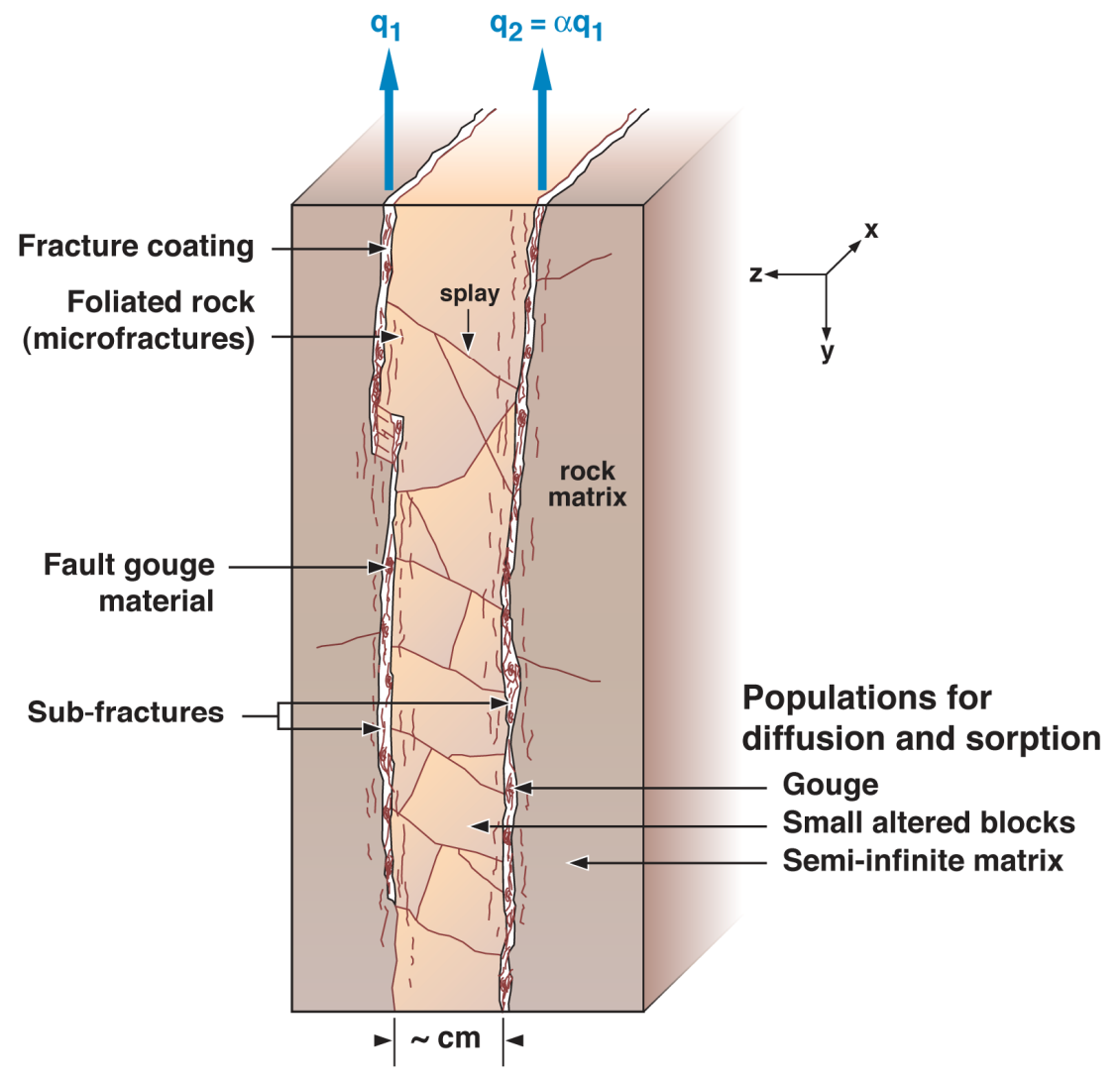

Figure 1. Complex fracture model (Tsang and Doughty, 2003; Mazurek et al., 2001). 

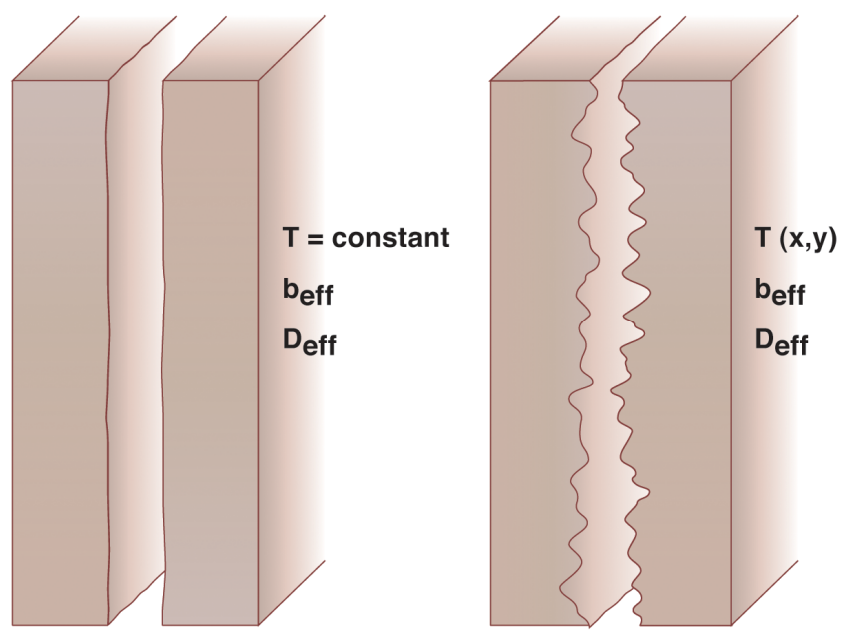

Figure 2. Schematic view of two versions of simple fracture model. 


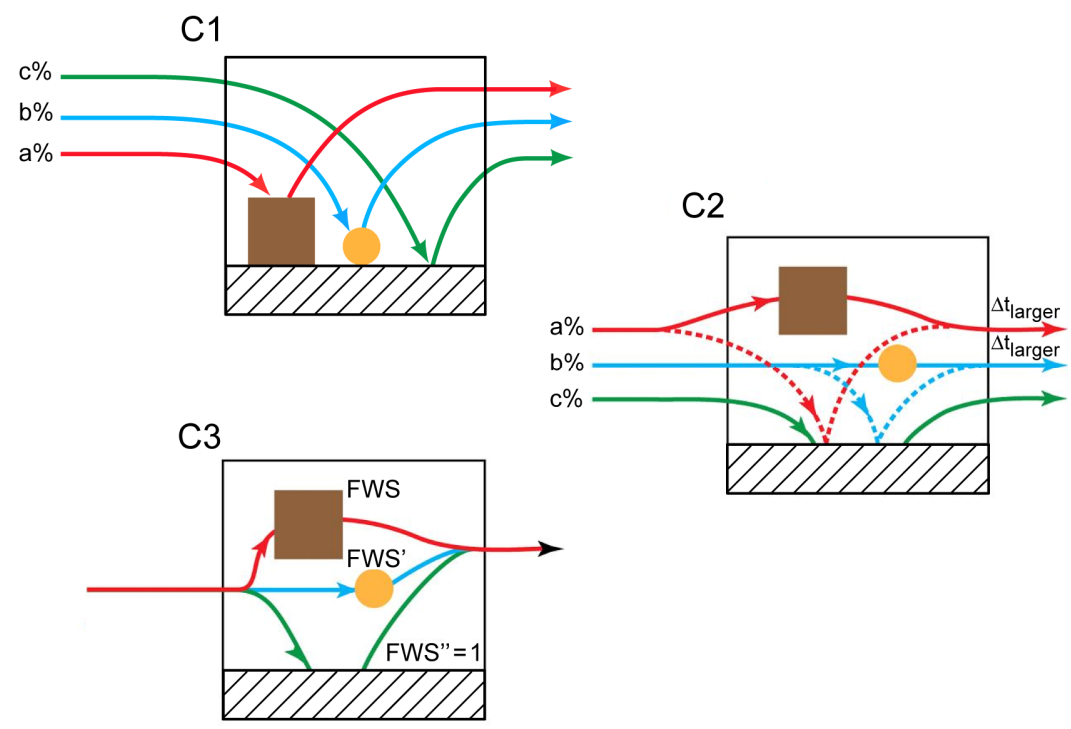

Figure 3. Three alternative prescriptions $\mathrm{C} 1, \mathrm{C} 2$ and $\mathrm{C} 3$ for calculating diffusion/sorption into the semi-infinite and finite populations. $\mathrm{C} 3$ is used in this paper. 
(a)
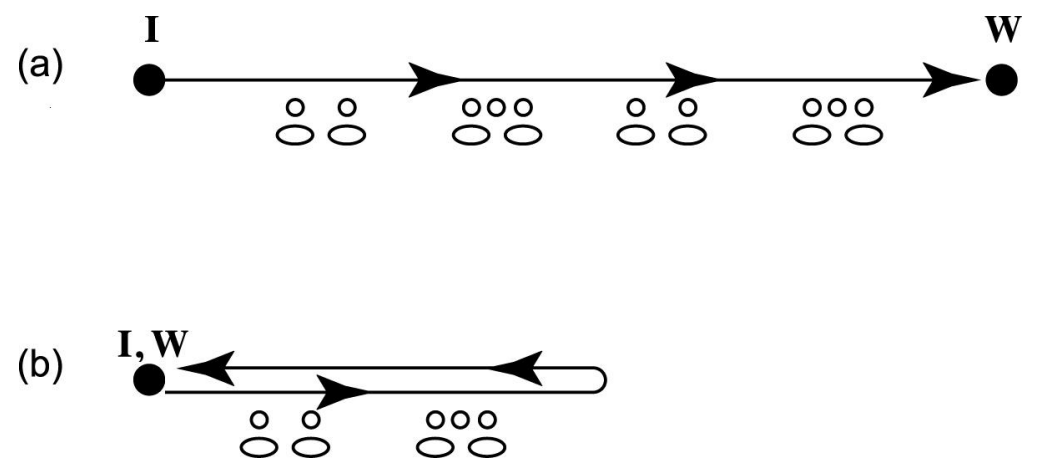

Figure 1. Schematic diagram of particle travel path during a two-well test (a) and a SWIW test (b). Arrows represent advection through the fracture and circles and ovals represent finite populations into which diffusion and sorption may occur. The semiinfinite rock matrix, also present, is not shown in this figure. I and $\mathrm{W}$ indicate injection and withdrawal wells respectively. 


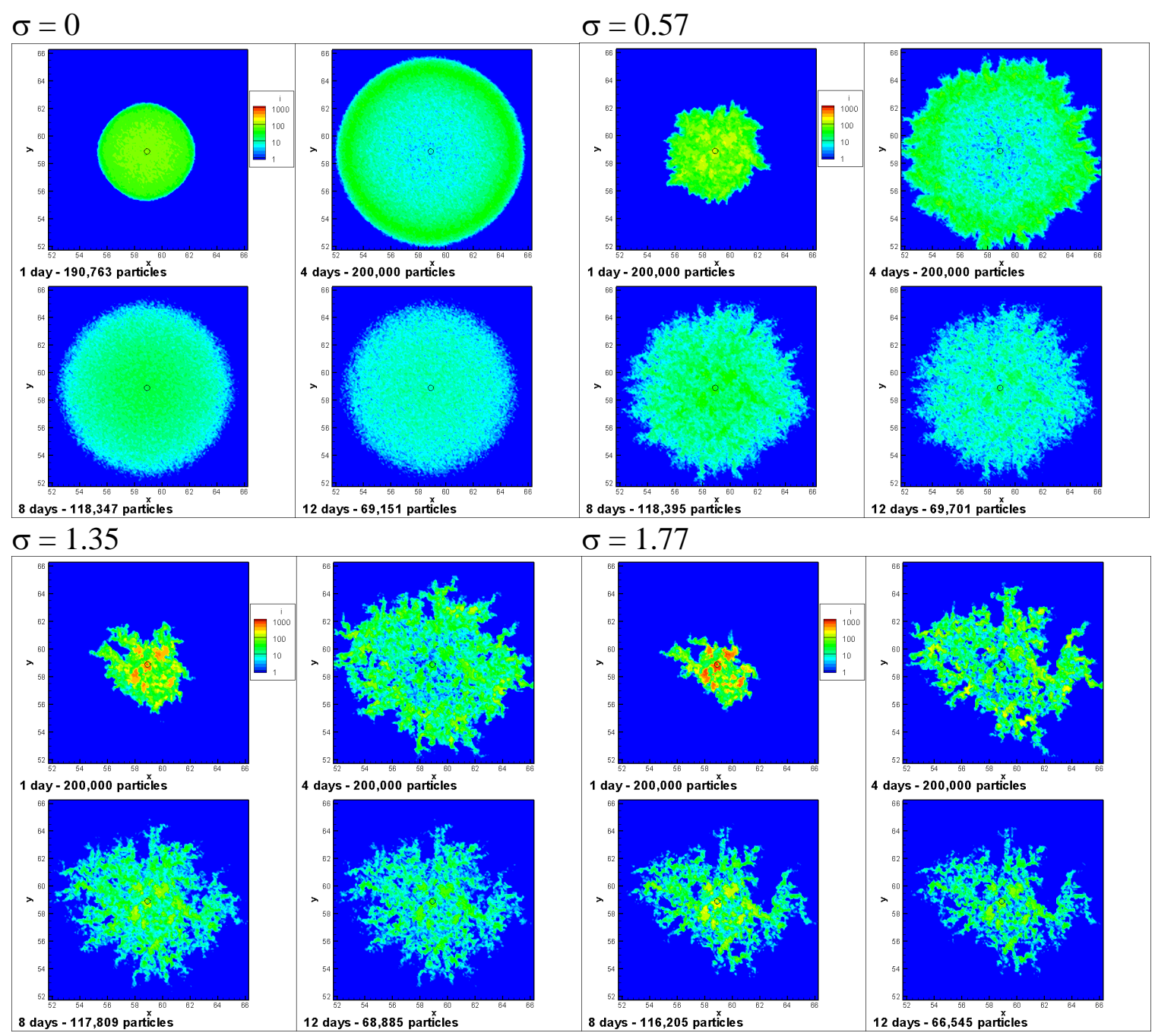

Figure 5. SWIW tracer distributions over the center part of the flow domain at 1, 4, 8 and 12 days for the simple fracture model employing various $\sigma$ values for short-correlation length heterogeneity. 


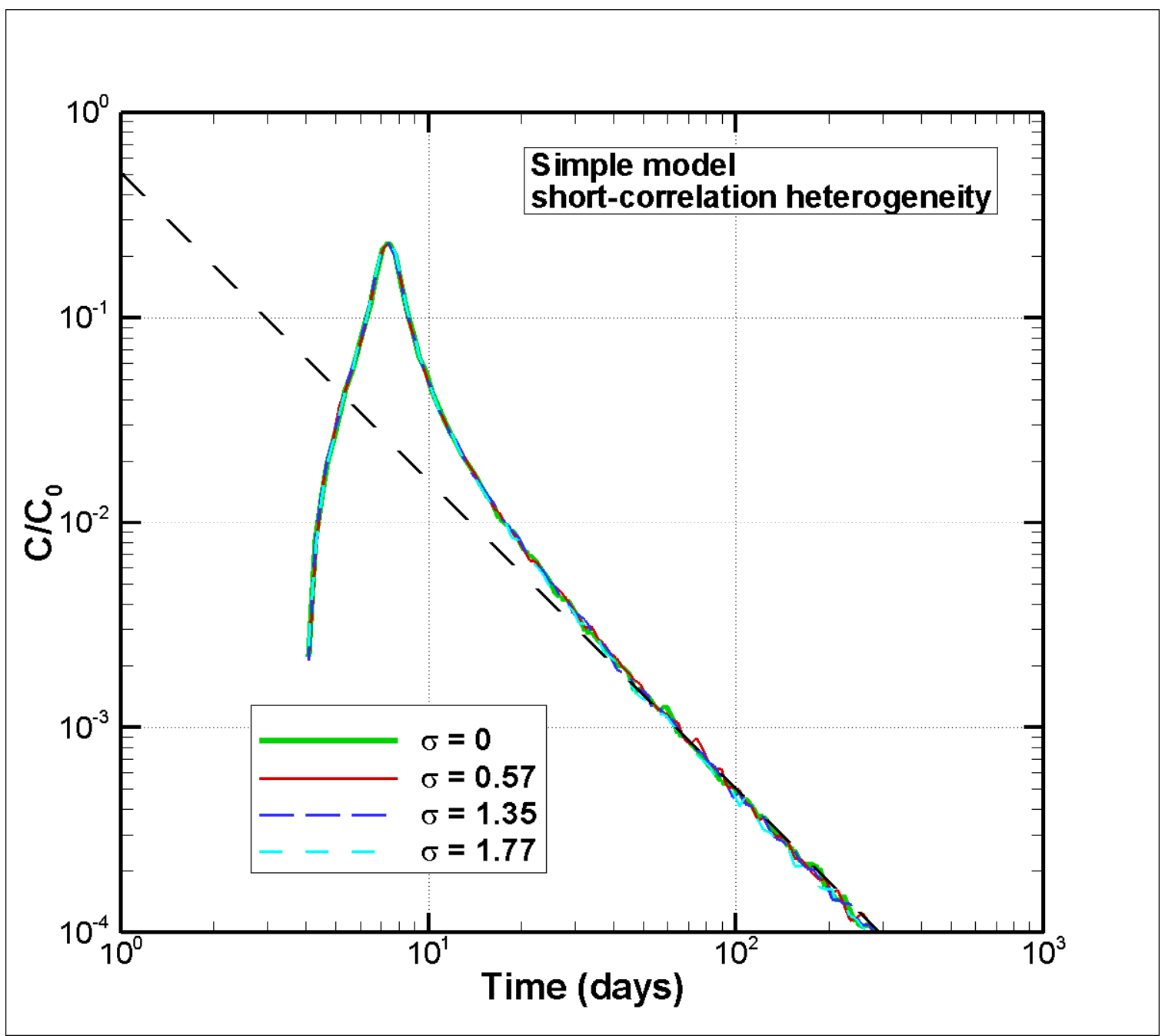

Figure 6. Tracer BTCs for the simple model with different values of $\sigma$ representing different levels of short-correlation heterogeneity. The dashed line shows a log slope of $-3 / 2$. 

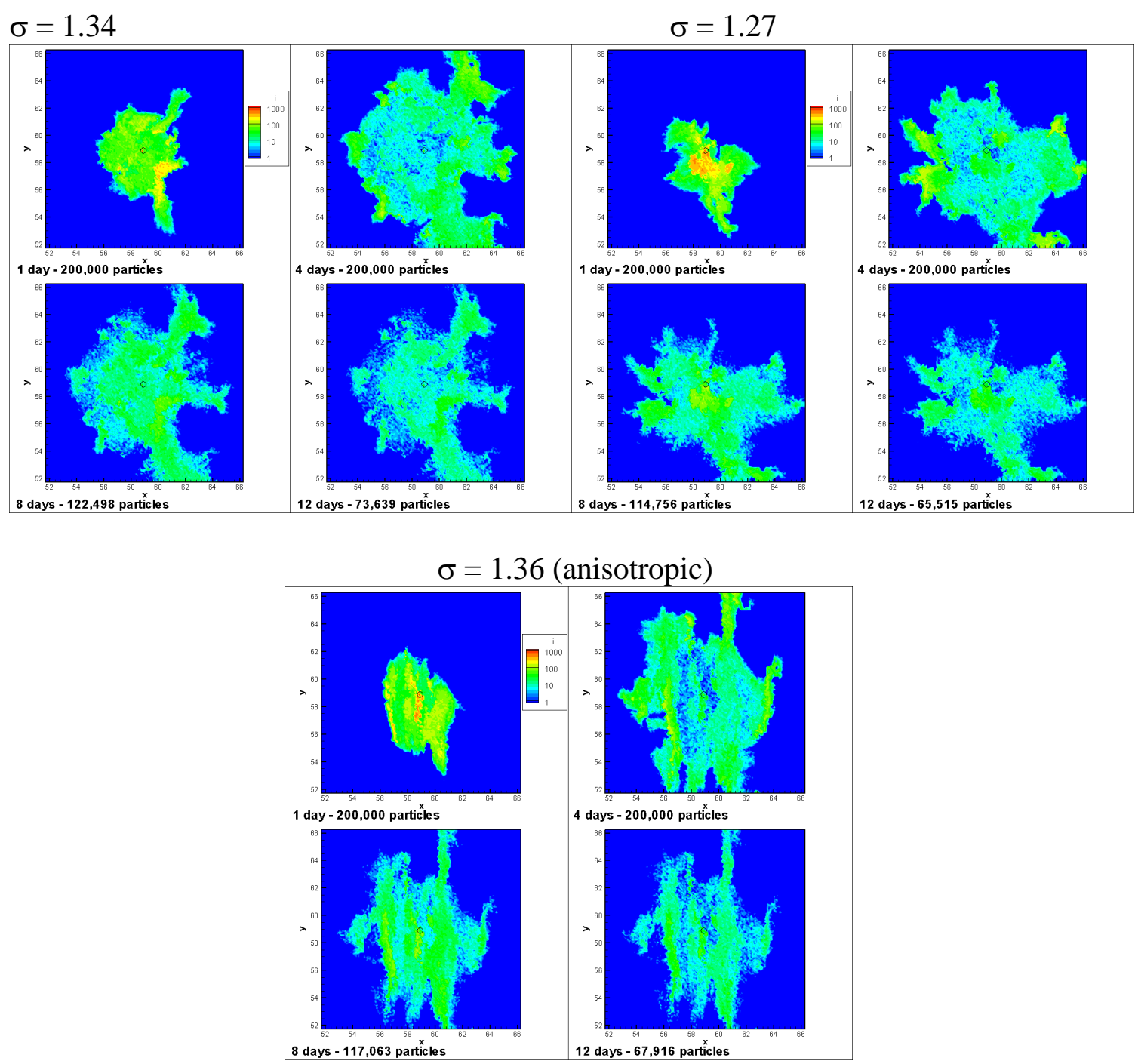

Figure 7. SWIW tracer distributions over the center part of the flow domain at 1, 4, 8 and 12 days for the simple fracture model employing various $\sigma$ values for long-correlation length heterogeneity 

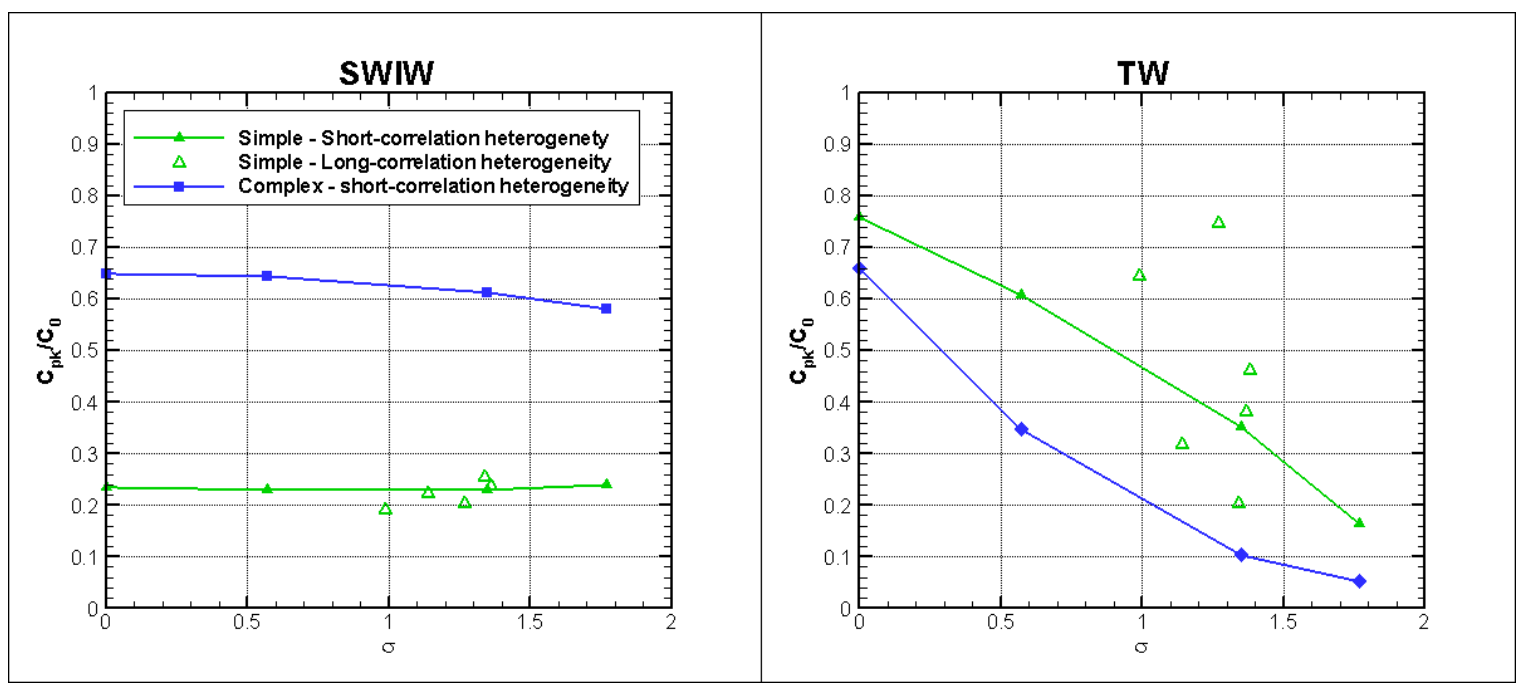

Figure 8. Peak concentration from the tracer BTCs for the simple and complex fracture models with short- and long-correlation length heterogeneity for different $\sigma$ values. Left frame: SWIW tests; right frame: two-well (TW) tests. 


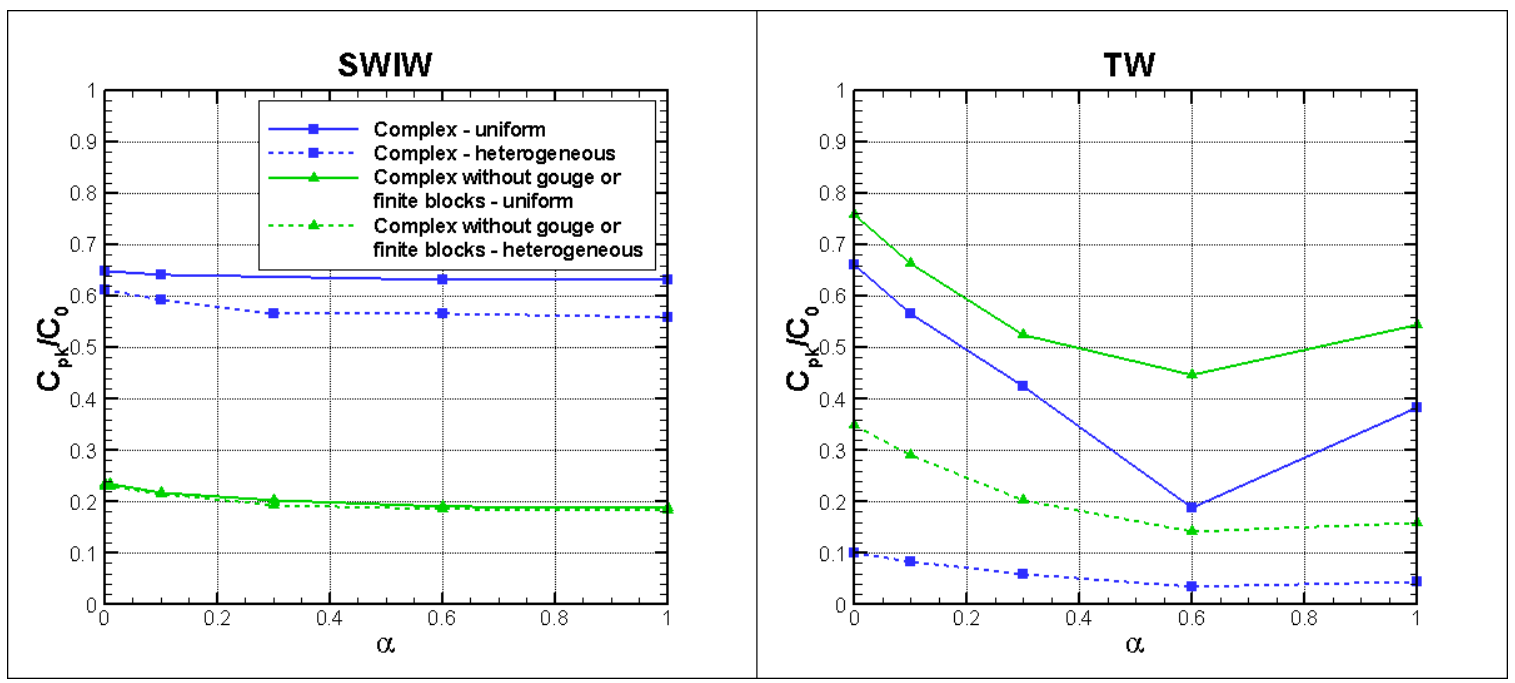

Figure 9. Peak concentration from the tracer BTCs for various values of $\alpha$, for a uniform and heterogeneous T fields. Left frame: SWIW tests; right frame: two-well (TW) tests 


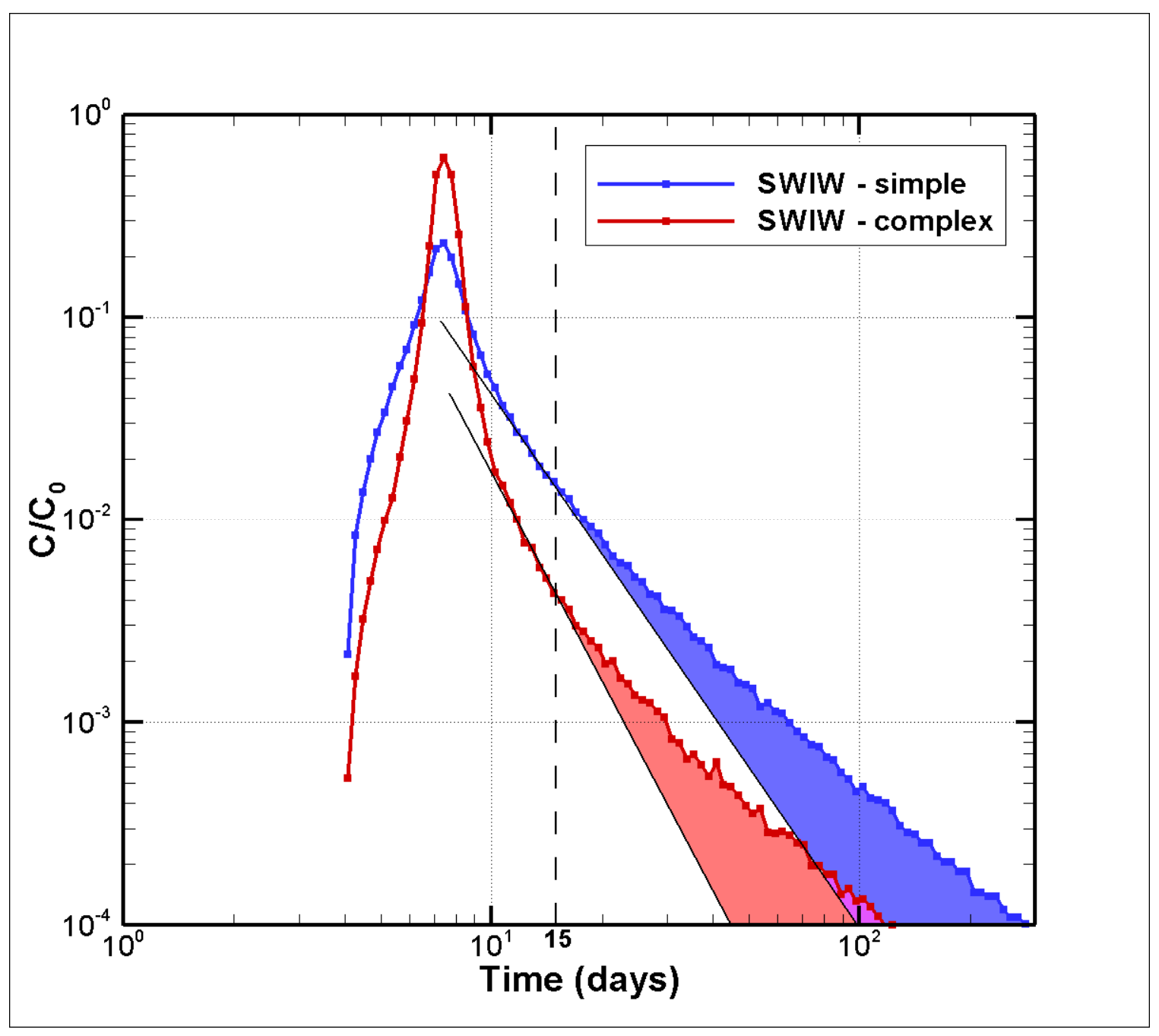

Figure 10. Comparison of tracer BTCs for simple and complex fracture models. If monitoring only continues for 15 days, the true late-time slope will not be observed. 


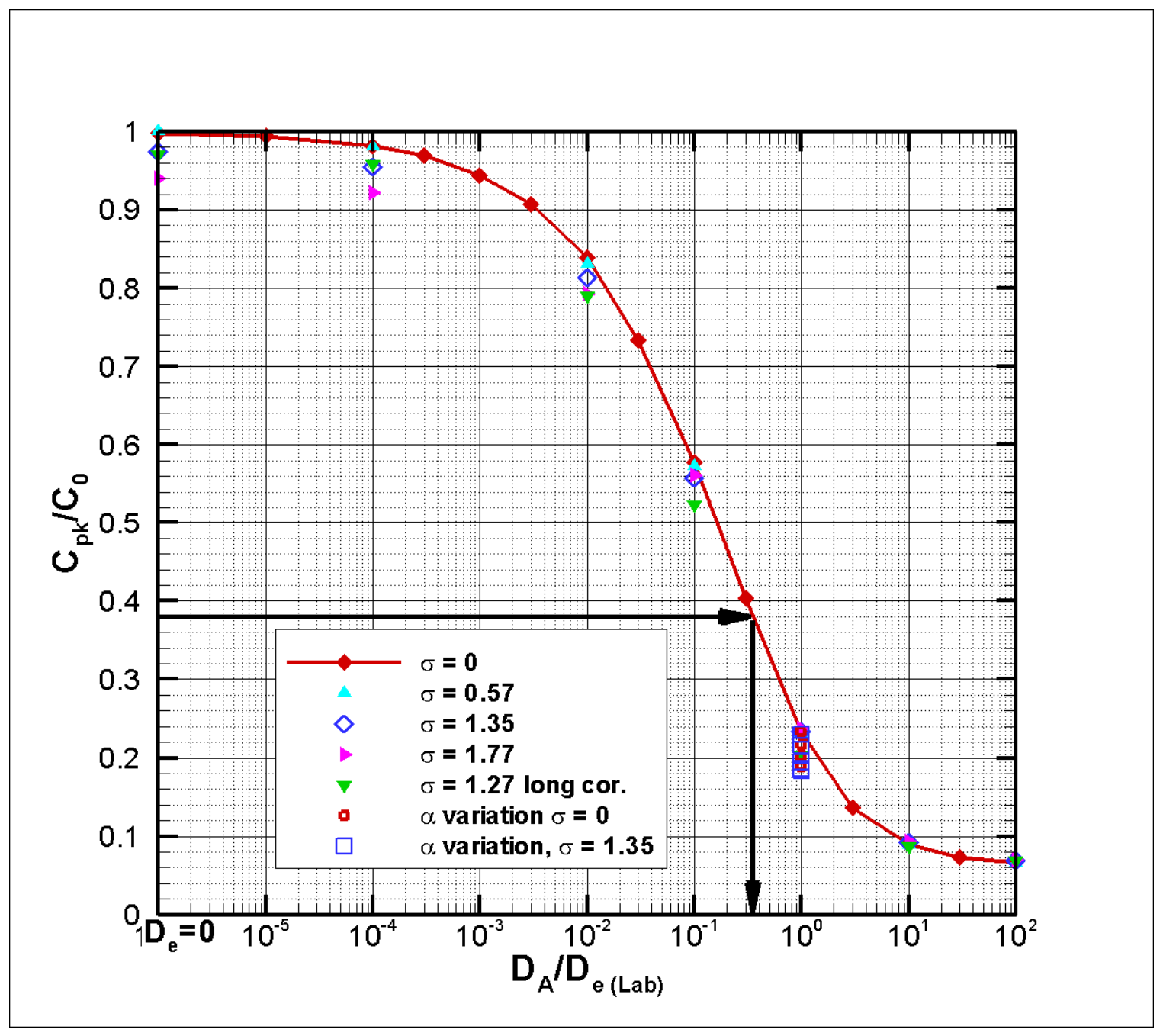

Figure 11. The effect of various parameters on peak concentration as a function of $D_{A}$ value for models with no gouge or small altered blocks. The different symbols represent cases with different values of $\sigma$ and $\alpha$ parameters. For all cases with $D_{A} \neq D_{e(L a b)}, \alpha=0$. 

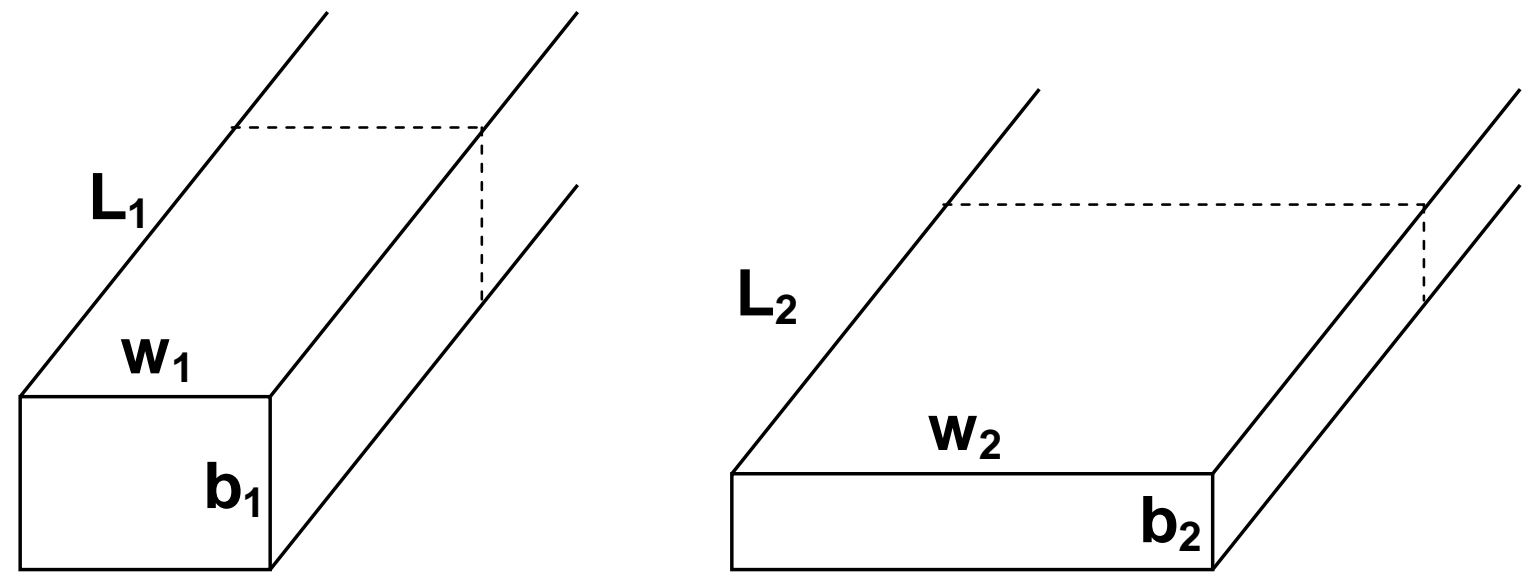

Figure 12. Schematic flow geometries with different values of FWS. 


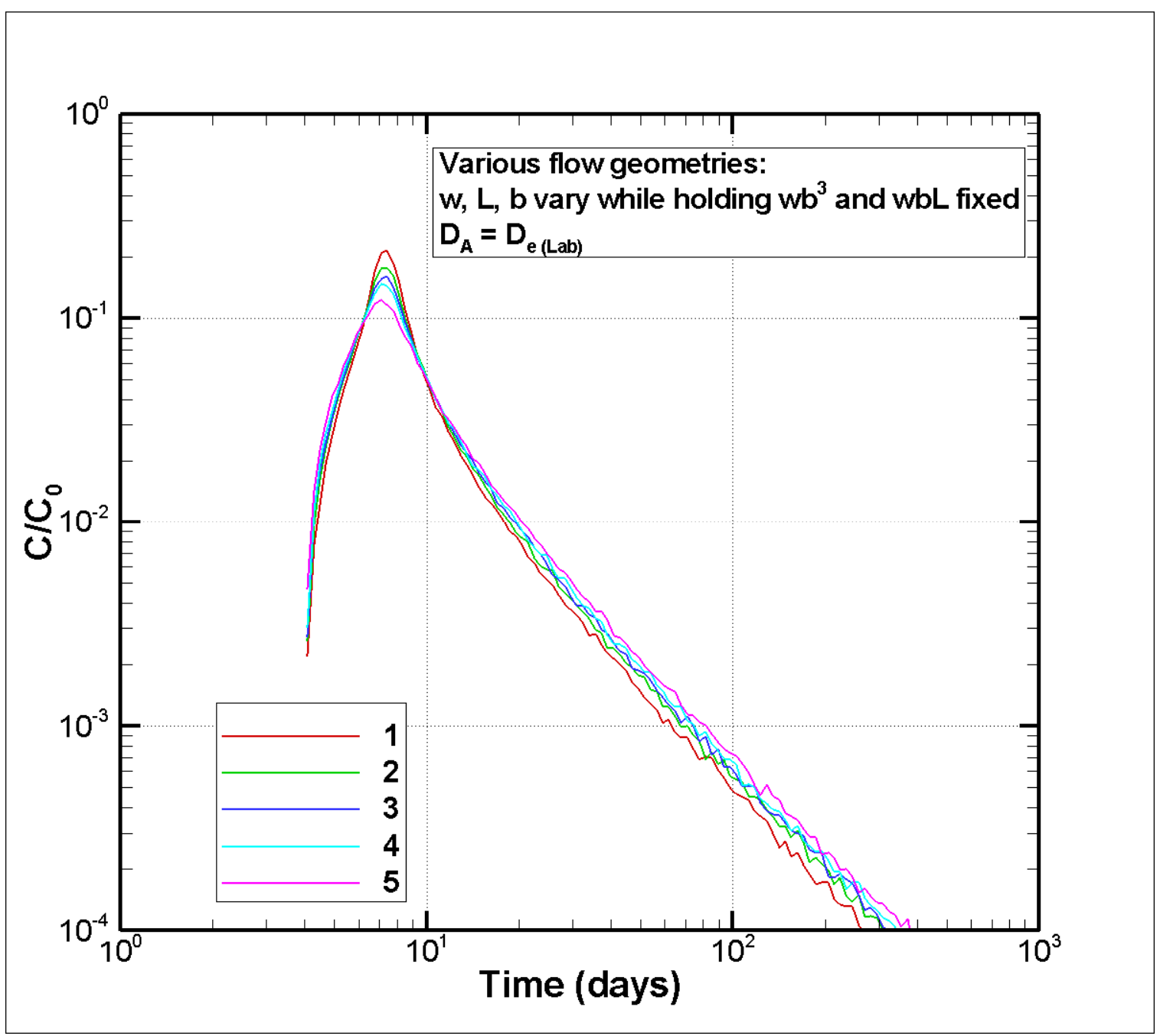

Figure 13. Tracer BTCs for schematic models with different flow geometries. 


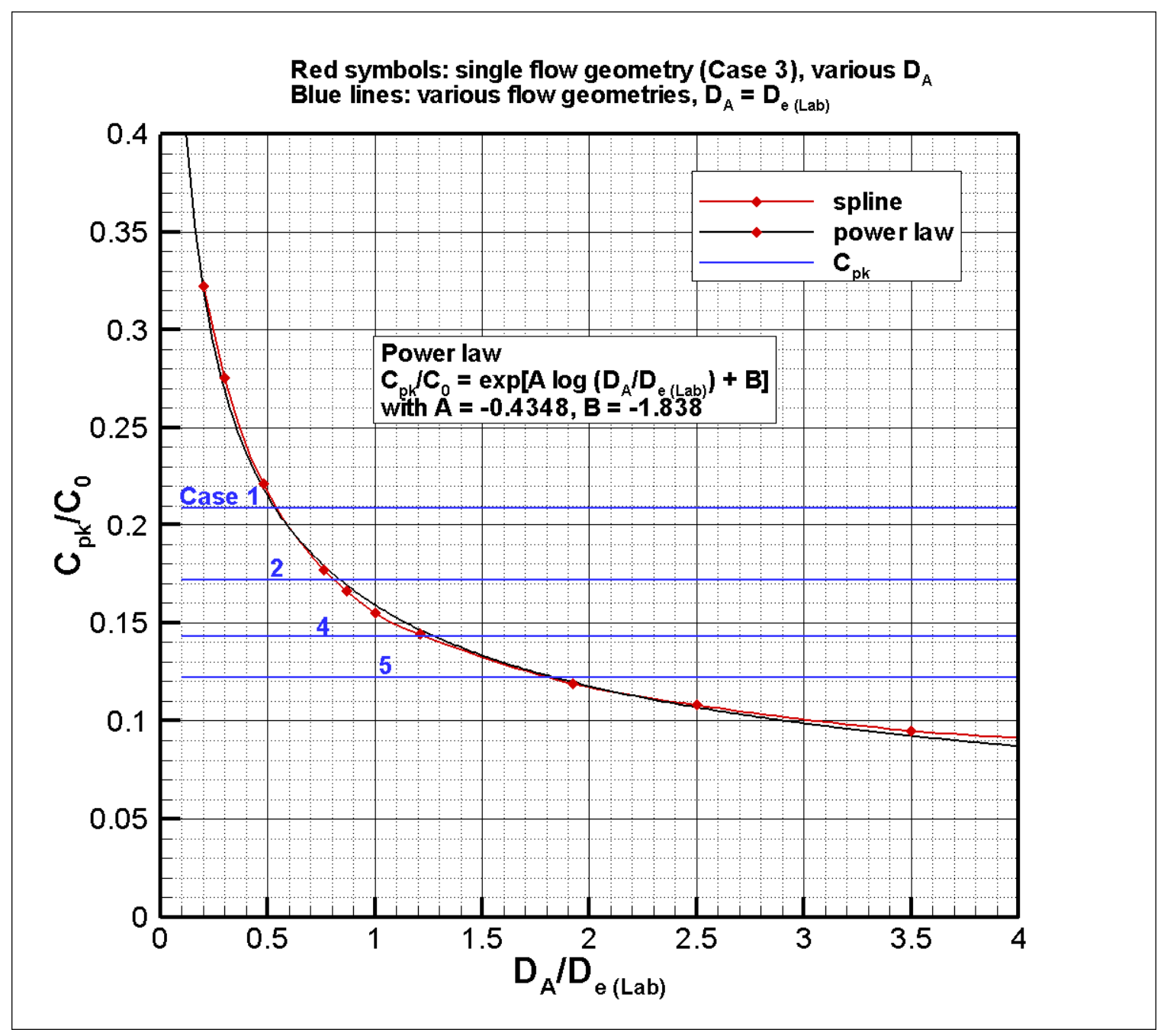

Figure 14. $C_{p k}$ as a function of $D_{A} / D_{e(L a b)}$ for a single flow geometry (red symbols) and corresponding spline fit (red line) and power-law fit (black line). $C_{p k}$ values obtained using $D_{e(L a b)}$ and different flow geometries are shown as blue lines. The intersection of the blue line and the black curve determines apparent diffusivity $D_{A}$. 